\title{
Perbandingan Penggunaan Media ICT dengan Media Manual pada Pembelajaran Statistika Siswa SMP Negeri 5 Panggang Gunungkidul
}

\author{
Desi Susilawati, Mudiyatun Sawiyah,Asnidar \\ Pascasarjana Pendidikan Matematika \\ Universitas Negeri Surabaya \\ e-mail: desisudaryanto08@gmail.com, mudi.gho24@gmail.com, asnidar.sakita@gmail.com
}

\begin{abstract}
ABSTRAK
Dunia telah mengalami kemajuan sangat pesat dibidang teknologi. Pemanfaatan teknologi secara tepat dalam dunia pendidikan akan sangat membantu terhadap proses pembelajaran. Salah satunya adalah penggunaan media ICT (Information and Communication Technology) dalam proses belajar mengajar di kelas. Pembelajaran dengan menggunakan media ICT membutuhkan sarana prasarana yang mendukung yaitu berupa komputer. SMP Negeri 5 termasuk salah satu sekolah di Gunungkidul yang terbilang cukup lengkap dan telah memiliki fasilitas berupa laboratorium computer. Selain itu kepemilikan computer atau laptop sudah bukan menjadi hal asing bagi siswa. Namun ada juga anggapan bahwa penggunaan media manual masih representatif untuk digunakan pada pembelajaran.

Berdasarkan hasil observasi, siswa kelas VIII mengalami kesulitan belajar pada mata pelajaran matematika, khususnya pada materi Statistika. Penggunaan media ICT diasumsikan dapat membantu mengatasi masalah belajar dan meningkatkan hasil belajar siswa sehingga dilakukan pengembangan media menggunakan model ADDIE. Penggunaan media manual juga dilakukan untuk mengetahui perbandingan pemanfaatan media ICT dan media manual. Analisis data diperoleh dari hasil pengisian daftar checklist dari angket siswa. Sedangkan, untuk mengetahui keefektifan media ICT dan media manual dalam meningkatkan hasil belajar digunakan analisis data menggunakan uji t.

Data yang diperoleh dari hasil uji coba berupa data kualitatif dan data kuantitatif. Hasil data kualitatif diperoleh dari data wawancara yang kemudian dilakukan analisis isi, sedangkan data kualitatif diperoleh dari hasil perhitungan angket dan hasil tes. Rata-rata hasil belajar siswa menggunakan media ICT 78,75 dengan simpangan baku 17,08. Rata-rata hasil belajar siswa menggunakan media manual 72,5 dengan simpangan baku 16,12. Berdasarkan hasil uji t dapat disimpulkan bahwa hasil belajar siswa menggunakan media ICT untuk materi statistika lebih baik daripada hasil belajar siswa menggunakan media manual. Jadi, media ICT statistika mata pelajaran matematika untuk siswa kelas VIII dinyatakan layak dan efektif untuk digunakan sebagai media pembelajaran di SMP Negeri 5 Panggang Gunungkidul.
\end{abstract}

Kata kunci: pengembangan, media ICT, media manual, model ADDIE

\begin{abstract}
The world has experienced a very rapid progress in technology. Utilization of appropriate technologies in education will be very helpful to the learning process. One is the media usage of ICT (Information and Communication Technology) in teaching and learning in the classroom. Learning by using ICT media requires infrastructure to support the form of a computer. SMP Negeri 5 Panggang Gunungkidul, including one of the schools which is quite complete and has facilities such as computer labs. Additionally ownership or laptop computer already is not a foreign thing for students. But there is also the notion that use of the manual is still representative for the media used in learning.
\end{abstract}


Based on observations, the eighth grade students with learning difficulties in mathematics, particularly in the matter of Statistics. The use of ICT media assumed that it could help overcome the problem of learning and improve student learning outcomes so do the media development using ADDIE models. The use of manual media also carried out to compare the use of ICT media and media manual. Analysis of the data obtained from the questionnaire filling a checklist of students. Whereas, to determine the effectiveness of ICT media and media user in improving learning outcomes used data analysis using the $t$ test.

Data obtained from the test results in the form of quantitative and qualitative data. Results of the qualitative data obtained from the interview data were then conducted content analysis, while qualitative data obtained from the calculation results of questionnaires and test results. The average results of student learning using ICT media 78.75 with a standard deviation of 17.08 . The average student learning outcomes using manual media 72.5 with a standard deviation of 16.12 . Based on $t$ test results can be concluded that the results of student learning using ICT media for statistical material better than the results of student learning using media manual. So, media ICT statistical mathematics courses for students of class VIII declared feasible and effective for use as a medium of learning in SMP Negeri 5 Panggang Gunungkidul.

Keywords: development, media, ICT, media manual, the model ADDIE

\section{Pendahuluan}

Matematika adalah salah satu mata pelajaran di sekolah yang menjadi momok bagi siswa dan dianggap sulit. Hal ini dikarenakan obyek kajian pada matematika bersifat abstrak sedangkan kebanyakan guru mengajarkan matematika begitu saja tanpa memperhatikan kondisi siswa.

Bruner membagi proses belajar siswa menjadi 3 tahapan yaitu tahap enaktif, ikonik, simbolik. Pada tahap enaktif siswa dituntut mempelajari pengetahuan dengan menggunakan benda konkret atau situasi nyata. Selanjutnya memasuki tahap ikonik siswa mempelajari suatu pengetahuan dalam bentuk gambar atau diagram sebagai perwujudan dari kegiatan yang menggunakan benda konkret atau nyata. Setelah itu siswa mulai mengalami proses berabstraksi pada tahap simbolik yaitu siswa mewujudkan pengetahuannya dalam bentuk simbol-simbol abstrak.

Berdasarkan pendapat Bruner, pembelajaran sebaiknya dimulai dengan menggunakan benda nyata terlebih dahulu. Oleh karena itu pada pembelajaran matematika guru sebaiknya menggunakan model atau benda nyata untuk topik-topik tertentu yang dapat membantu pemahaman siswa tentang konsep yang akan diajarkan.

Statistika adalah adalah salah satu pokok bahasan yang sudah tidak asing lagi bagi siswa karena penggunaannya dalam kehidupan sehari-hari namun ternyata hal tersebut tidak menjadi jaminan bahwa siswa akan memiliki pemahaman yang baik tentang statistika. Di SMP sekarang ini materi tentang statistika diberikan di kelas VIII semester 2 di mana konten yang diajarkan pun masih bersifat dasar seperti yang termuat dalam Permendikbud no. 24 tahun 2016 tentang KD (kompetensi dasar) untuk materi statistika yaitu:

3.10 Menganalisis data berdasarkan distribusi data, nilai rata-rata, median, modus, dan sebaran data untuk mengambil kesimpulan, membuat keputusan, dan membuat prediksi.

4.10 Menyajikan dan menyelesaikan masalah yang berkaitan dengan distribusi data, nilai ratarata, median, modus, dan sebaran data untuk mengambil kesimpulan, membuat keputusan, dan membuat prediksi. [1] 
Seperti kita tahu dunia telah mengalami kemajuan sangat pesat dibidang teknologi. Pemanfaatan teknologi secara tepat dalam dunia pendidikan akan sangat membantu terhadap proses pembelajaran. Salah satunya adalah penggunaan media ICT (Information and Communication Technology) dalam proses belajar mengajar di kelas [2,3]. Pembelajaran dengan menggunakan media ICT membutuhkan sarana prasarana yang mendukung yaitu berupa komputer. SMP Negeri 5 termasuk salah satu sekolah di Gunungkidul yang terbilang cukup lengkap dan telah memiliki fasilitas berupa laboratorium komputer. Selain itu kepemilikan komputer atau laptop sudah bukan menjadi hal asing bagi siswa. Namun ada juga anggapan bahwa penggunaan media manual masih representatif untuk digunakan pada pembelajaran.

Berdasarkan hasil observasi, siswa kelas VIII mengalami kesulitan belajar pada mata pelajaran matematika, khususnya pada materi statistika. Penggunaan media ICT diasumsikan dapat membantu mengatasi masalah belajar dan meningkatkan hasil belajar siswa sehingga dilakukan pengembangan media menggunakan model ADDIE. Penggunaan media manual juga dilakukan untuk mengetahui perbandingan pemanfaatan media ICT dan media manual.

Salah satu ciri pembelajaran yang baik yaitu siswa tidak hanya menjadi penerima pasif namun siswa dilibatkan secara aktif dalam pembelajaran sehingga dimungkinkan bagi siswa untuk membangun pemahamannya secara utuh dan bermakna dalam bimbingan guru.

Dengan memperhatikan berbagai faktor di atas, kami mengembangkan suatu media pembelajaran yang dapat membantu memahamkan materi statistika kepada siswa. Selain mempelajari konsep, penyajian materi menjadi lebih menyenangkan karena siswa juga terlibat secara aktif dalam penggunaan media. Menurut penelitian yang dilakukan Teoh \& Neo (2007:28) menyatakan bahwa, "The students' perceptions on the use of multimedia and interactivity were very positive. Students agreed that learning with interactivity and multimedia was interesting and engaging; at the same time they found this method of learning useful and favourable." yang berarti pandangan siswa tentang penggunaan multimedia dan interaktivitas sangat positif [4].

Siswa setuju bahwa pembelajaran dengan interaktivitas dan multimedia adalah menarik dan melibatkan siswa sehingga pada saat yang sama siswa menemukan metode belajar yang berguna dan menguntungkan. Media yang kami kembangkan ini kami beri nama Papan Memomequ.

Pada penelitian ini kami ingin mengetahui perbandingan penggunaan media ICT dengan media manual. Oleh karena itu penelitian ini berjudul "Perbandingan PenggunaanMedia ICT dengan Media Manual pada Pembelajaran Statistika Siswa SMP Negeri 5 Panggang Gunungkidul". Pembelajaran dilakukan menggunakan model pembelajaran langsung, dengan dua kelas yaitu satu kelas menggunakan media ICT dan kelas satunya menggunakan media manual.

Berdasarkan latar belakang masalah, dapat dibuat rumusan masalah yaitu (1) Bagaimana desain pengembangan media ICT dengan menggunakan model ADDIE (2) Manakah yang lebih efektif dari penggunaan media ICT dan media manual.

\section{Metode}

Metode pengembangan yang digunakan dalam pengembangan media ini adalah model ADDIE yang merupakan salah satu model desain pembelajaran [5]. Menurut Tegeh dan Kirna (2010) model ADDIE terdiri dari 5 (lima) langkah yaitu: (1) analisis (analyze), (2) perancangan (design), (3) pengembangan (development), (4) implementasi (implementation), dan (5) evaluasi (evaluation) [6]. Subjek coba pada penelitian ini adalah satu orang ahli isi mata 
pelajaran dan desain pembelajaran, serta siswa 2 kelompok uji masing-masing berjumlah 16 orang siswa.

Metode pengumpulan data yang digunakan pada penelitian ini adalah metode pencatatan dokumen dan angket. Metode pencatatan dokumen menggunakan instrument pengumpulan data berupa agenda kerja. Metode angket menggunakan instrument pengumpulan data berupa kuesioner. Kuesioner digunakan untuk mengumpulkan hasil review ahli isi mata pelajaran dan ahli desain pembelajaran, siswa saat uji perorangan, uji kelompok kecil, dan uji lapangan. Jenis data yang didapat dari penelitian ini adalah data kuantitatif dan data kualitatif. Data yang telah terkumpul kemudian dianalisis menggunakan uji $\mathrm{t}$ dan uiji $\mathrm{F}$.

\section{Hasil dan Pembahasan}

Pengembangan Media menggunakan model ADDIE melalui beberapa tahapan:

1. Analisis

i. Identifikasi Masalah dengan mempertimbangkan lack of resources (kurangnya sumber belajar), lack of mitivation (kurangnya motivasi), dan lack of knowledge and skill (kurangnya pengetahuan dan keterampilan)

Pada tahap ini diperoleh hasil berupa: kondisi sekolah yang kurang lengkap secara fasilitas ketersediaan buku teks dan jaringan internet, kondisi motivasi siswa yang cukup rendah, dan pola mengajar guru yang relatif monoton.

ii. Menentukan Tujuan Pembelajaran yaitu siswa dapat menentukan mean, median, modus, dan kuartil.

iii. Menganalisis Siswa.

Pada tahap ini diketahui kondisi siswa yang rata-rata kemampuannya rendah dan gaya belajar siswa secara umum adalah kinestetik.

iv. Mengaudit Sumber yang Ada

a) Content resources

Materi yang digunakan untuk mengembangkan media ini adalah materi statistika. Materi ini dalam Kurikulum 2013 terdapat pada kelas VIII semester 2, KD 3.10 dan KI 4.10 yang berbunyi:

3.10 Menganalisis data berdasarkan distribusi data, nilai rata-rata, median, modus, dan sebaran data untuk mengambil kesimpulan, membuat keputusan, dan membuat prediksi.

4.10 Menyajikan dan menyelesaikan masalah yang berkaitan dengan distribusi data, nilai rata-rata, median, modus, dan sebaran data untuk mengambil kesimpulan, membuat keputusan, dan membuat prediksi. [7]

b) Technology resources

Untuk mengembangkan media pembelajaran ini tidak dibutuhkan teknologi yang kompleks. Media ini dibuat dengan sterofom, karton dan kain flannel karena bahan ini mudah didapat, gampang dibentuk, tahan lama, dan harganya terjangkau.

\section{c) Instructional resources}

Di sekolah sudah terdapat laboratorium komputer meskipun dengan jumlah terbatas demikian juga dengan LCD. Namun penulis membuat media pembelajaran ini dengan tujuan agar siswa dapat merasakan atau terlibat secara langsung dalam pembelajaran sehingga belajar menjadi 
sesuatu hal yang menyenangkan dan bermakna. Siswa lebih paham konsep dan tidak sekedar menghapal.

\section{d) Human resources}

Pihak yang terlibat dalam pengembangkan media pembelajaran adalah penulis sebagai guru mata pelajaran di sekolah masing-masing.

v. Merekomendasikan sistem penyampaian yang potensial (termasuk perkiraan biaya). Tahap ini diestimasikan jumlah biaya yang dibutuhkan dalam pengembangan media. Pada pengembangan media ini biaya total dibatasi maksimal Rp 100.000,00

vi. Menyusun Sebuah Rencana Manajemen Proyek

2. Desain

i. Melakukan inventarisasi tugas

ii. Tahap penyusunan tujuan pembelajaran

iii. Tahap menentukan strategi penilaian

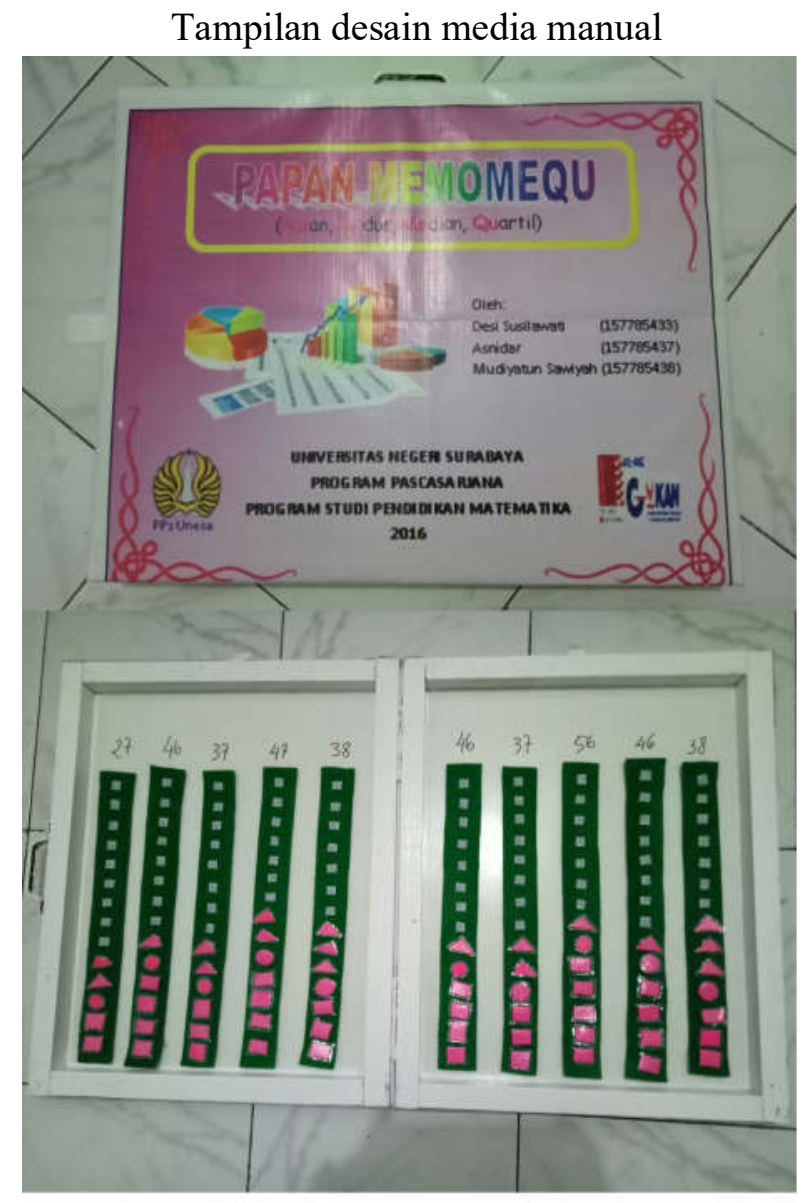

Tampilan Desain Media ICT 

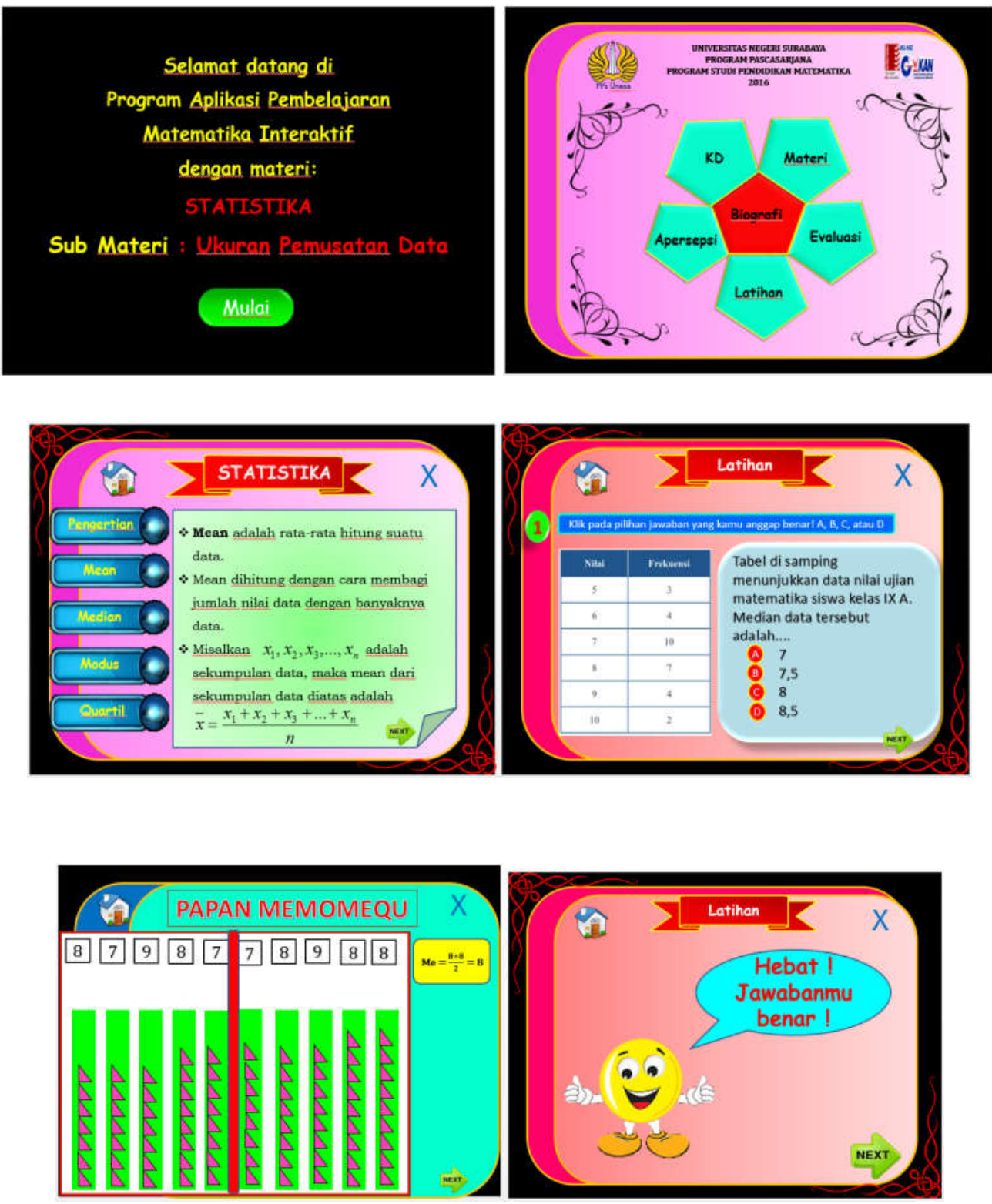

3. Pengembangan

Media dikembangkan dengan validasi ahli

4. Implementasi

Media diimplementasikan di SMP Negeri 5 Panggang Gunungkidul

5. Evaluasi

Evaluasi dilakukan dengan melihat hasil dari implementasi yang telah dilakukan. Pada pembahasan akan dipaparkan secara rinci hasil belajar siswa dengan menggunakan media ICT dan media manual.

Diketahui hasil penelitian sebagai berikut:

\begin{tabular}{|l|l|r|}
\hline & Manual (2) & ICT (1) \\
\hline
\end{tabular}


Perbandingan Penggunaan Media ICT dengan Media Manual pada Pembelajaran Statistika Siswa SMP Negeri 5 Panggang Gunungkidul

\begin{tabular}{|l|c|c|}
\hline Rata-rata & 72.5 & 78.75 \\
\hline Simpangan Baku & 16.12 & 17.08 \\
\hline Varian & 260.00 & 291.67 \\
\hline $\mathrm{n}$ & 16 & 16 \\
\hline
\end{tabular}

Klaim:

Hasil belajar siswa menggunakan media ICT untuk materi statistika lebih baik dari hasil belajar siswa menggunakan media manual atau $\mu_{1}-\mu_{2}>0$

Karena Varians kedua populasi tidak diketahui maka dilakukan pengujian kesamaan varians dua populasi dengan langkah-langkah:

1. $H_{0}: \sigma_{1}^{2}=\sigma_{2}^{2}$

2. $H_{0}: \sigma_{1}^{2} \neq \sigma_{2}^{2}$

3. $\alpha=0.05$

4. Kriteria penolakan $H_{0}$

Tolak $H_{0}$ jika

$$
F=\frac{S_{1}^{2}}{S_{2}^{2}}>F_{0.05}(15,15)=2.4
$$

5. Menghitung Nilai F

$F=\frac{S_{1}^{2}}{S_{2}{ }^{2}}=\frac{291.67}{260.00}=1.12$

6. Kesimpulan

Karena $F=1.12<2.4=F_{0.05}(15,15)$ maka $H_{0}$ diterima, sehingga $\sigma_{1}{ }^{2}=\sigma_{2}{ }^{2}$

Dengan demikian statistic yang dipakai untuk menguji klaim adalah:

$t=\frac{\left(\overline{x_{1}}-\overline{x_{2}}\right)-\mu_{0}}{S_{p} \sqrt{\frac{1}{n_{1}}+\frac{1}{n_{2}}}}$ dengan $S_{p}^{2}=\frac{S_{1}^{2}\left(n_{1}-1\right)+S_{2}^{2}\left(n_{2}-1\right)}{n_{1}+n_{2}-2}$

dan derajat bebas $v=n_{1}+n_{2}-2$

Selanjutnya menguji Klaim.

1. $H_{0}: \mu_{1}-\mu_{2} \leq 0$

2. $H_{0}: \mu_{1}-\mu_{2}>0$

3. $\alpha=0.05$

4. Kriteria penolakan $H_{0}$

Tolak $H_{0}$ jika

$t>t_{\alpha, v}=t_{0.05,30}=1.645$

5. Menghitung nilai $\mathrm{t}$ 


$$
\begin{aligned}
S_{p}{ }^{2} & =\frac{S_{1}^{2}\left(n_{1}-1\right)+S_{2}^{2}\left(n_{2}-1\right)}{n_{1}+n_{2}-2} \\
& =\frac{291.67(16-1)+260(16-1)}{16+16-2} \\
& =275.8333 \\
S_{p} & =\sqrt{275.8333} \\
& =16.608231 \\
t= & \frac{\left(x_{1}-\overline{x_{2}}\right)-\mu_{0}}{1} \\
S_{p} \sqrt{\frac{1}{n_{1}}+\frac{1}{n_{2}}} & \frac{\left(78.75^{2}-72.5^{2}\right)-0}{16.608231 \sqrt{\frac{1}{15}+\frac{1}{15}}} \\
= & \frac{945.3125}{6.0644685} \\
= & 155.87722
\end{aligned}
$$

6. Kesimpulan

Karena $t=155.87722>1.645=t_{\alpha, v}=t_{0.05,30}$ maka $H_{0}$ ditolak dan $H_{1}$ diterima sehingga cukup alas an untuk menyatakan bahwa hasil belajar siswa menggunakan media ICT untuk materi statistika lebih baik dari hasil belajar siswa menggunakan media manual

\section{Penutup}

Berdasarkan hasil dan pembahasan dapat disimpulkan yaitu (1) Desain media ICT yang siap digunakan siswa (2) Hasil belajar pada kelompok siswa yang menggunakan media ICT lebih baik dari pada kelompok siswa yang menggunakan media manual.

\section{Ucapan Terimakasih}

Pada penelitian ini kami ucapkan banyak terimakasih kepada Dr. Elly Matul Imah, M.Kom selaku dosen mata kuliah Pengembangan Media Pembelajaran; Bapak Punidi, S.Pd.M.M selaku Kepala SMP Negeri 5 Panggang Gunungkidul yang telah memberikan izin penelitian serta kepada Bapak Sunardi, S.Pd selaku guru mata pelajaran matematika SMP Negeri 5 Panggang Gunungkidul.

\section{A. DAFTAR PUSTAKA}

[1] Permendikbud No 24 Tahun 2016. Lampiran 15 tentang KI dan KD Matematika $S M P / M T s$.

[2] Tim PPPPTK. 2013. Pemanfaatan Alat Peraga Matematika 1. Diklat Online 2013 P4TK Matematika Yogyakarta. 
Perbandingan Penggunaan Media ICT dengan Media Manual pada Pembelajaran Statistika Siswa SMP Negeri 5 Panggang Gunungkidul

[3] Widyantini, Th dan Guntoro, Sigit Tri. 2010. Penggunaan Alat Peraga Dalam Pembelajaran Matematika.Yogyakarta: PPPPTK Matematika

[4] Teoh, B. S. P. \& Neo, T. K. 2007. "Interactive Multimedia Learning: Students' Attitudes And Learning Impact In An Animation Course". The Turkish Online Journal of Educational Technology. Volume 6, Isue 4, Halaman. 28-37.

[5] Branch, Robert Maribe.2009. Instructional Design: The ADDIE Approach. Springer

[6] Tegeh, I M. dan I M. Kirna. 2010. Metode Penenlitian Pengembangan Pendidikan. Singaraja:Universitas Pendidikan Ganesha.

[7] Kemdikbud. 2015. Buku Guru Matematika SMP/MTs Kelas VIII. Jakarta: Kementrian Pendidikan dan Kebudayaan. 